\title{
РАСЧЕТ ЖЕЛЕЗОБЕТОННОЙ ПЛИТЫ ПЕРЕКРЫТИЯ ПРИ ВОЗДЕЙСТВИИ ПОВЫШЕННЫХ ТЕМПЕРАТУР ПОЖАРА
}

\author{
Поклонський В.Г. ${ }^{1 *}$, ,Круковський П. $\Gamma^{1} .$, Новак С. В. ${ }^{2}$ \\ ${ }^{1}$ Інститут технічної теплофізики Національної академії наук України \\ ${ }^{2}$ Інститут державного управління та наукових досліджень з ичиільного захист \\ ІНФОРМАЦИЯ ПРО СТАТЬЮ

Надійшла до редакції:
01.11.2020 рецензування:
Пройшла
16.11.2020
ключЕВЫЕ СлОВА:
огнестойкость,
железобетонные
конструкции,
стандартным
температурным
режимом,
температурный режим
реального пожара,
численного п
моделирования

Постановка проблемы. Все более актуальной в последние годы становится задача определения пределов огнестойкости железобетонных строительных конструкций. Повышенный интерес к этой проблеме вызван ростом высотности зданий, возрастающей сложностью и ответственностью зданий, повреждение конструкций которых при пожаре может привести к катастрофическим последствиям. Дополнительные трудности возникают при расчете и проектировании ответственных конструкций с большими пролетами, развитыми поперечными сечениями, насыщенными арматурой различных видов. В то же время, за последнее десятилетие отмечается рост количества пожаров. При проектировании должна быть гарантирована защита несущей конструктивной системы здания от

\footnotetext{
*v.poklonsky@ukr.net. https//doi.org/10.33269/nvcz.2020.69-82 2518-1777/@2020 ІДУНДЦ Ц3
}

обрушения при пожаре, обеспечиваемая именно огнестойкостью строительных конструкций. Расчет конструкций на огнестойкость должен отражать их реальную работу при совместном действии статической нагрузки и высокотемпературных воздействий пожара.

Использование расчетных методов дает возможность на стадии проектирования оценить огнестойкость железобетонных конструкций, проверить их соответствие строительным нормам, разработать предложения по обеспечению необходимой степени огнестойкости здания. Для обеспечения установленных требований пожарной безопасности при проектировании железобетонных конструкций, в части расчетов на огнестойкость, разработан Еврокод 2 и соответствующий ему национальный стандарт ДСТУ-Н Б ЕN $1992-$ 
1-2 [1]. В этом документе приведено три метода оценки огнестойкости железобетонных конструкций: табличные данные, упрощенные методы расчета и уточненные методы расчета.

При оценке огнестойкости конструкций уточненными методами расчета учитываются все факторы, которые оказывают существенное воздействие на напряженно-деформированное состояние конструкции при пожаре. Определяют повышение и распространение температуры в конструкции в заданный момент времени (теплотехнический расчет) и механическое поведение конструкции (статический расчет), при этом учитывается соответствующий сценарий пожара. Для учета особенностей работы железобетона в реальных конструкциях при высокотемпературных воздействиях необходимо применение различных теорий деформирования и прочности бетона и арматурной стали. Точность результатов расчета напряженно-деформированного состояния конструкций при пожаре взаимосвязана с точностью задания параметров математической модели, в том числе свойств бетона.

Учитывая наличие ряда преимуществ расчетных методов оценки огнестойкости железобетонных конструкций перед экспериментальными методами, например, отсутствие необходимости проведения материалозатратных испытаний, актуальными следует считать исследования, направленные на дальнейшее их совершенствование и развитие.

Анализ последних исследований и публикаций. Проблеме огнестойкости железобетонных конструкций посвящены работы Б.Г.Демчины [2], С.Ф. Клованича [3], М.И. Колякова [2], А.Ф. Милованова [4], В.М. Ройтмана [5], С.Л. Фомина [6], А.И. Яковлева [7] , V.K.R. Kodur [8], T. Gernay[9], J. Franssenc[9] и многочисленные работы других исследователей.

Исследования, проведенные Б.А. Альтшулером [10], В.И. Корсуном [11] ,
А.П. Кричевским [12], А.Ф. Миловановым [4], С.Л. Фоминым [7], А.И. Яковлевым [7], U.Schneider [13], Y. Anderberg [14], R. Jansson [15] показывают, что прочность и деформативность бетона при повышенных температурах значительно изменяются и зависят от температуры нагрева и продолжительности пожара, типа заполнителя, влажности бетона, масштабного фактора, наличия добавок, температурного режима, приложения нагрузки и нагрева.

Рассмотрение и анализ состояния вопроса по расчетам на огнестойкость железобетонных конструкций свидетельствует о том, что назрела настоятельная необходимость в проведении исследований, направленных на повышение точности расчетов. Решение таких задач невозможно без применения многофункциональных программных комплексов и высокопроизводительной компьютерной техники.

В национальном стандарте по проектированию огнестойких железобетонных конструкций [1] рассматривается уточненный метод расчета. Однако этапы и процедуры проведения расчетов этим методом не установлены, сформулированы лишь основные требования для создания расчетной модели уточненного метода и указывается на необходимость проверки точности расчетных моделей по результатам соответствующих испытаний.

С конца 60-х годов прошлого столетия развиваются численные методы решения задач механики деформируемого твердого тела с применением ЭВМ. На сегодняшний день на основе метода конечных элементов разработано большое число коммерческих расчетных комплексов. Одним из наиболее используемых программных комплексов является ANSYS. Он позволяет проводить вычисления любой сложности, что делает этот пакет программ безусловным лидером среди остальных конкурентов. ANSYS был выбран в качестве основного в силу его 
объективных преимуществ перед аналогами. Программный комплекс содержит множество специальных опций, которые позволяют получить решение с учетом нелинейных эффектов, таких как пластичность, большие деформации, ползучесть, большие перемещения, контакт, изменение жесткости, температурная зависимость, анизотропия материала. Особо следует отметить возможность проведения связанных многодисциплинарных расчетов.

В общем случае математическая модель состоит из моделей теплового и напряженно-деформированного состояний строительных конструкций при пожаре. Математическая модель учитывает радиационно-конвективный теплообмен в газовой среде от источника теплового воздействия к поверхности строительной конструкции, кондуктивный теплообмен в этой конструкции, радиационноконвективный теплообмен от этой конструкции в окружающую среду с поверхности конструкции, которая не обогревается. Компоненты математической модели отражают основные физические процессы, которые непосредственно влияют на точность оценки огнестойкости отдельной строительной конструкции, в том числе пространственный характер распределения температур и напряжений и неоднородность строительной конструкции по структуре и физическим свойствам ее отдельных элементов.

Численное моделирование напряженнодеформированного состояния конструкций без каких-либо существенных ограничений в ANSYS основано на реализации метода конечных элементов в форме перемещений. Достоверность результатов, полученных с помощью метода конечных элементов, определяется в основном достоверностью и степенью обоснованности используемых физических моделей материала и соответствующих определяющих соотношений. Комбинация конкретных соотношений для условия текучести, закона течения и закона упрочнения/разупрочнения определяет ту или иную модель пластического поведения материала. В ANSYS моделируются следующие типы пластического поведения: классическое линейное кинематическое упрочнение; полигональное кинематическое упрочнение; линейное изотропное упрочнение; полигональное изотропное упрочнение; анизотропное поведение; модели бетона Друкера-Прагера, Ментери-Вильяма, Вильяма-Варнке, Базанта. Кроме того, пользователь может задать свой вариант пластической модели.

Наибольшее число специальных опций для бетона представлено в ANSYS при использовании модели Друкера - Прагера. Математическая модель критерия прочности Друкера-Прагера [16], разработанная в 1952 году, определяет разрушение материалов под влиянием пластических деформаций. Уравнение состояния Друкера-Прагера применимо для горных пород и бетона, построено на приближении к закону МораКулона в виде конической поверхности.

Цель статьи. Разработка методики применения уточненного метода расчета на огнестойкость железобетонных конструкций в программном комплексе ANSYS, работающих в условиях стандартного температурного режима и режима воздействия реального пожара, с учетом реальных свойств материалов, полученных путем анализа имеющихся в литературе экспериментальных данных и характеристик материалов, приведенных в Еврокодах.

Для достижения поставленной цели решались следующие задачи:

1. Анализ состояния вопроса в области уточненных методов расчета на огнестойкость железобетонных конструкций.

2. Проведение численного моделирования теплового состояния железобетонной плиты перекрытия и получение полей распределения температур в бетоне и арматуре при стандартном температурном режиме и режиме реального пожара. 
3. Проведение статического расчета и получения напряженно-деформированного состояния железобетонной конструкций плиты перекрытия при совместном воздействии силовых и температурных нагрузок.

Изложение основного материала. Моделирование работь железобетонной конструкиии в программном комплексе ANSYS. Для решения прочностной задачи необходимо задать модуль упругости, коэффициент Пуассона, коэффициент температурного расширения, диаграммы деформирования и модель разрушения для бетона. Все параметры являются температурозависимыми.

Свойства бетона и стали при повышенных температурах устанавливают в соответствии с ДСТУ-Н Б ЕN 1992-1-2 [1], ДСТУ-Н Б ЕN 1993-1-2 [17] и ДСТУ-Н Б EN 1994-1-2 [18].

Диаграммы деформирования бетона при одноосном сжатии важны также и для построения модели деформирования бетона, относящейся к неодноосным напряженным состояниям. Выбор вида диаграмм может существенно повлиять на точность получаемых решений. Прочностные и деформационные свойства при одноосном сжатии бетона при повышенных температурах определяются по диаграмме «напряжения-деформации», представленной в ДСТУ-Н Б ЕN 1992-1-2 [1].

Железобетонные конструкции при пожаре работают в условиях совместных силовых и температурных воздействий. Испытывают неодноосные напряженные состояния, которые приводят к изменению их механического состояния и предельных условий, что необходимо учитывать при расчетах. Поведение бетона при двухосном и трехосном нагружении изменяется по сравнению с его поведением при одноосном сжатии и растяжении [19]. Как следует из результатов экспериментальных исследований при нормальной температуре, наличие бокового обжатия в условиях двух и трехосного сжатия повышает сопротивление бетона действию сжимающих напряжений. Наибольший прирост прочности при неравномерном двухосном сжатии составляет $30 \div 40 \%$, а в случаях трехосного неравномерного сжатия прочность образцов может превосходить призменную в несколько раз и повышается с ростом уровня бокового обжатия. Однако для области сжатия с растяжением характерно значительное снижение прочности, увеличивающееся с ростом уровня растягивающих напряжений. Поэтому в статье учитываются объемные напряженные состояния в бетоне. При задании параметров расчетной модели предел прочности при двухосном сжатии принят в соответствии с рекомендациями, приведенными в [3].

В моделе бетона поверхность текучести состоит из двух пересекающихся конических поверхностей Друкера-Прагера, (рисунок 1) [20]. Поверхность текучести построена в пространстве главных напряжений и описывается соответствующими уравнениями. Для построения начальной поверхности текучести используется три параметра: предел прочности при одноосном растяжении; предел прочности при одноосном сжатии; предел прочности при двухосном сжатии. 


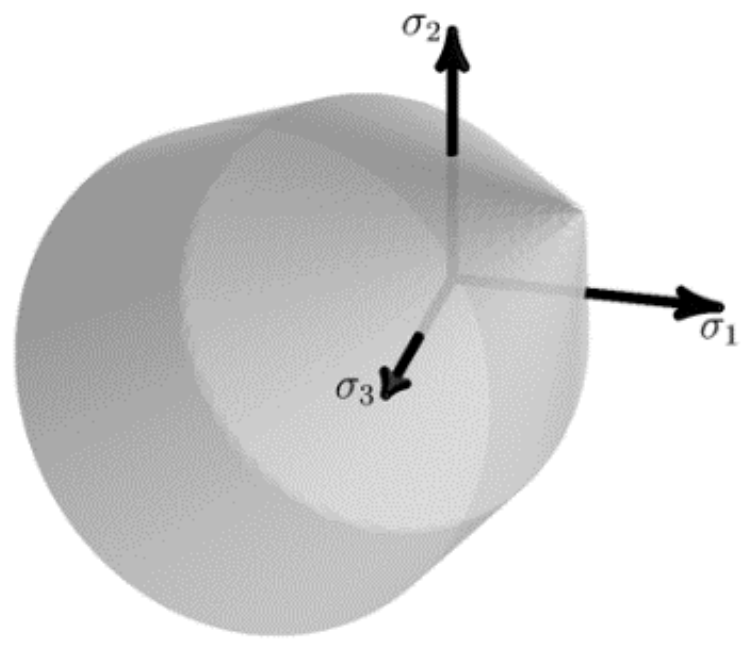

Рисунок 1 - Комбинированная поверхность, состоящая из поверхностей текучести Друкера-Прагера при сжатии и растяжении

Модель бетона Вилама-Варнке

Растяжение и растяжение-сжатие поверхности текучести Друкера-Прагера определяется как:

$$
f_{D P_{t}}=\frac{\sigma_{e}}{\sqrt{3}}+\beta_{t} \sigma_{m}-\sigma_{Y t}
$$

где $\sigma_{e}$ - эквивалентные напряжения и

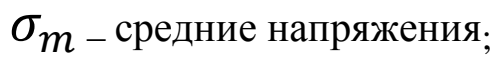

$\beta_{t}$ и $\sigma_{Y t}$ - константы, определяемые одноосным пределом прочности на растяжение $R_{t}$ и одноосным пределом прочности на сжатие $R_{c}$ :

$$
\begin{aligned}
\beta_{t} & =\frac{\sqrt{3}\left(R_{c} \Omega_{c}-R_{t} \Omega_{t}\right)}{R_{c} \Omega_{c}+R_{t} \Omega_{t}}, \\
\sigma_{Y t} & =\frac{\left.2 R_{c} \Omega_{c} R_{t} \Omega_{t}\right)}{\sqrt{3}\left(R_{c} \Omega_{c}+R_{t} \Omega_{t}\right)},
\end{aligned}
$$

$\Omega_{c}$ и $\Omega_{t}$ являются функциями упрочнения / разупрочнения при сжатии и растяжении, которые зависят от напряжения и переменных упрочнения.

Для поверхности текучести ДругераПрагера при растяжении и растяжениисжатии пластический потенциал составляет:

$$
Q_{D P t}=\frac{\sigma_{e}}{\sqrt{3}}+\delta_{t} \beta_{t} \sigma_{m}
$$

Для нагрузки сжатия поверхность текучести Друкера-Прагера:

$$
f_{D P_{c}}=\frac{\sigma_{e}}{\sqrt{3}}+\beta_{c} \sigma_{m}-\sigma_{Y c} \Omega_{c},(5)
$$

где константы $\beta_{c}$ и $\sigma_{Y t}$ связаны с прочностью на двухосное сжатие $R_{b}$ и прочностью на одноосное сжатие $R_{C}$ посредством:

$$
\begin{aligned}
& \beta_{c}=\frac{\sqrt{3}\left(R_{b}-R_{c}\right)}{2 R_{b}-R_{c}} \\
& \sigma_{Y t}=\frac{R_{b} R_{c}}{\sqrt{3}\left(2 R_{b}-R_{c}\right)} .
\end{aligned}
$$

Пластический потенциал при сжатии составляет:

$$
Q_{D P_{c}}=\frac{\sigma_{e}}{\sqrt{3}}+\delta_{c} \beta_{c} \sigma_{m}
$$

где $\delta_{c}$ параметр дилатанции при сжатии.

Железобетон является комплексным материалом, состоящим из бетона и стальной арматуры, которые работают совместно, но обладают различными механическими и реологическими свойствами, которые в условиях высокотемпературного нагрева меняются в различной степени. Применен “дискретный” подход, с представлением арматуры отдельными стержнями. Бетон и арматура моделируются объемными элементами. Подход не требует привязки сетки конечных элементов к шагу арматуры, что позволяет применять его к задачам с реальными размерами. Возможность учитывать характер совместной работы бетона и арматуры при нагреве - появление усилий из-за разности температурных деформаций, и другие эффекты. Такой подход целесообразен при воспроизведении экспериментов. 
Воздействие пожара на железобетонную конструкцию является нестационарным процессом. Нестационарный тепловой анализ используется программным комплексом для получения распределения температурных полей в железобетонной конструкции. Проектирование железобетонной плиты перекрытия выполнялось в модуле Design Modeller программы ANSYS. Затем осуществлялись последовательно расчёты в модулях TRANSIENT THERMAL и STATIC STRUCTURAL.

Компьютерная модель железобетонной плиты перекрытия, составленная в ANSYS, содержит следующие типы конечных элементов: SOLID186, CONTA174, TARGE170, SURF154. SOLID186объемный (трехмерный) гексаэдрический квадратичный элемент, имеющий двадцать узлов (рисунок 2). Элемент имеет квадратичное представление перемещений и в состоянии использовать нерегулярную форму сетки.

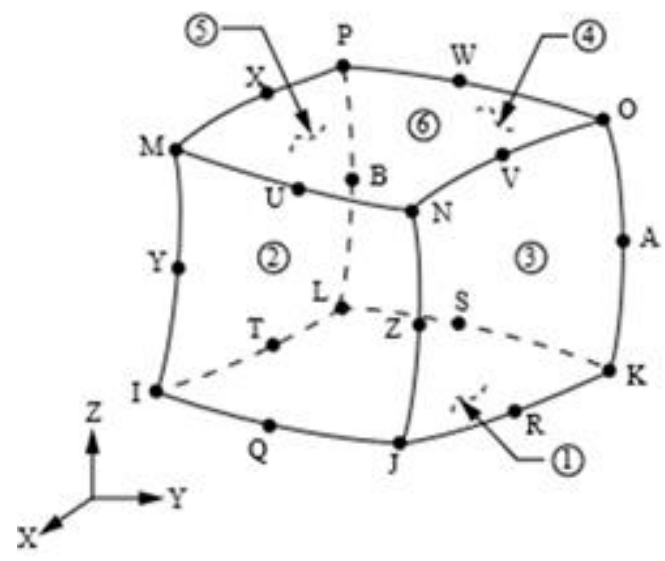

Рисунок 2 - Общий вид пространственного конечного элемента Solid186

Компьютерная модель железобетонной плиты перекрытия, составленная в ANSYS

Для взаимодействия между бетоном и арматурой вводятся контактные элементы. Контактные элементы воспринимают контактные взаимодействия, передачу усилий между одним и другим элементом. Принцип контактных пар позволяет решить задачу установления совместности на границе раздела между бетоном и арматурой. CONTA174 - элемент для представления контакта и скольжения между двумя поверхностями в 3D пространствах. TARGE170- элемент используется для представления ответных трёхмерных поверхностей для связи с контактным элементом CONTA174. Имеет восемь узлов.

Конечный $\quad$ элемент $\quad$ SURF154 используется для различных нагрузок и поверхностных эффектов при трехмерном структурном анализе. Он наложен на поверхность области указанных трехмерных элементов. Температуры вводятся как нагрузки на тело элемента в узлах. Геометрия, расположение узлов и система координат для этого элемента показаны на рис. 3.

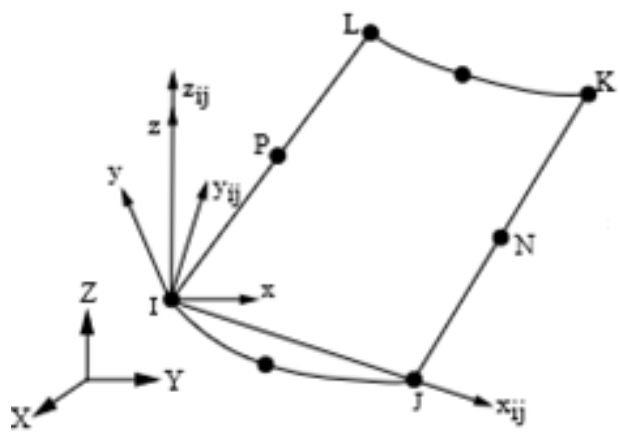

Рисунок 3 - Общий вид поверхностного элемента SURF154

Компьютерная модель железобетонной плиты перекрытия, составленная в ANSYS

Для решения задачи нестационарной теплопроводности необходимо задать значения коэффициентов теплопроводности, теплоемкости, а также плотность бетона как функции температуры.

Выполнены расчетные исследования железобетонной плиты и результаты сопоставлены с экспериментальными и расчетными данными [21] при стандартном температурном режиме и температурном режиме реального пожара (сценарий 3 ). 


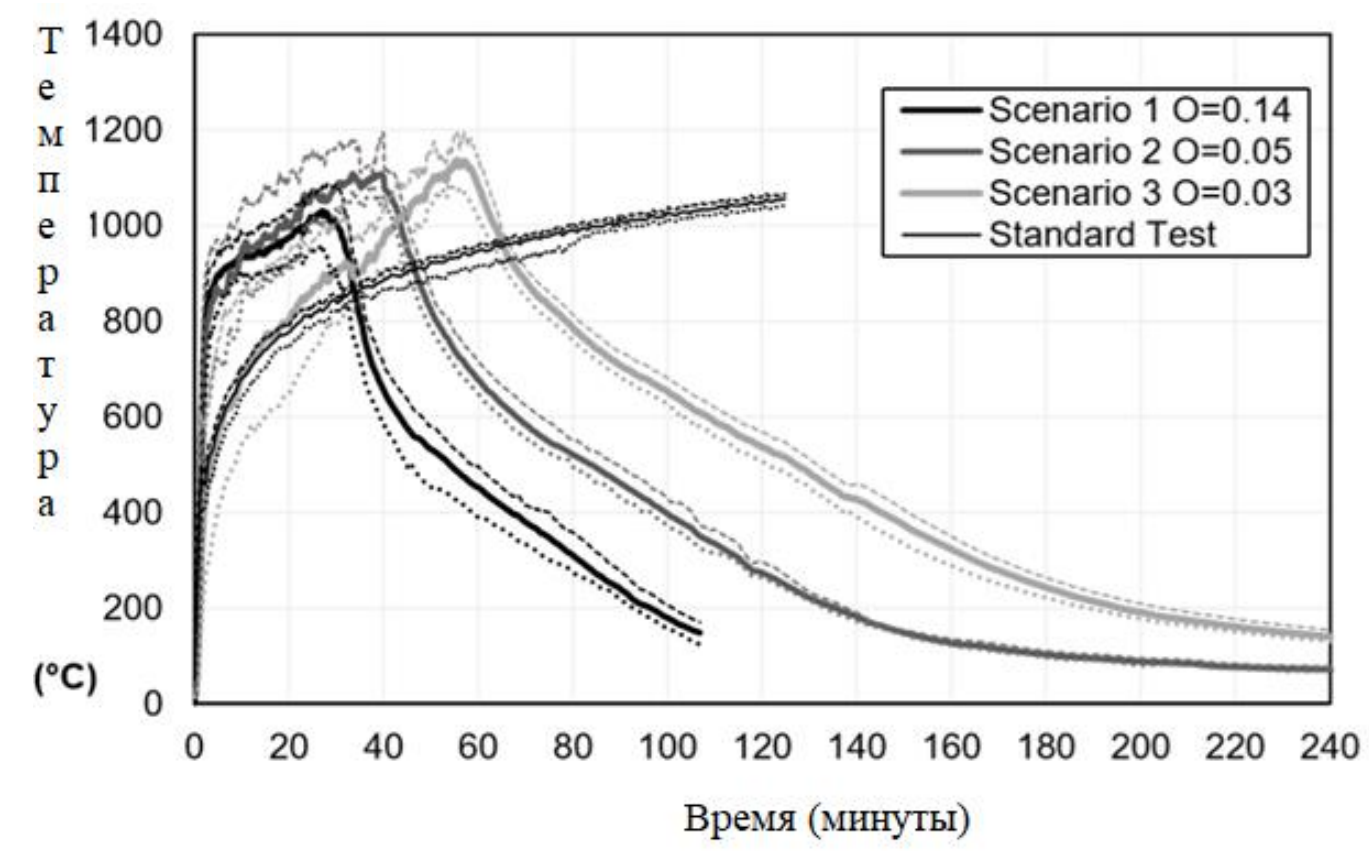

Рисунок 4 - Температура в печи [21]

Плотность тяжелого бетона при нормальной температуре составляет 2400 $\kappa г / \mathrm{M}^{3}$. В расчетах учитывается изменение плотности бетона при повышенных температурах от потери воды.

Плотность стали принята независимой

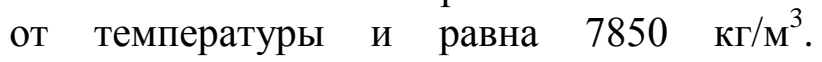
Вызванное температурой изменение свойств в бетоне гораздо сложнее, чем в арматуре из-за миграции влаги, процессов влаго и газообмена, а также значительных изменений компонентов в разных видах бетона.

Начальная температура железобетонной конструкции до пожара принималась равной $20{ }^{\circ} \mathrm{C}$. Температура окружающего воздуха над открытой поверхностью плиты также принимается равной $20^{\circ} \mathrm{C}$ и остается неизменной в течение всей продолжительности пожара. Условия радиационно-конвекционного нагрева от горячих газов к нижней поверхности плиты и охлаждения плиты в окружающую среду принятые при расчетах по стандартному температурному режиму приведены в табл. 1.

Таблициа 1 - Условия радиационноконвекционного нагрева

\begin{tabular}{|c|c|c|c|c|}
\hline $\begin{array}{l}\text { № } \\
\text { п/ } \\
\text { п }\end{array}$ & Наименование величины & 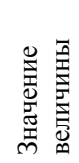 & 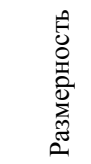 & 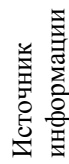 \\
\hline 1 & $\begin{array}{l}\text { Степень черноты поверхностей } \\
\text { железобетонной конструкции }\end{array}$ & 0,7 & & {$[1]$} \\
\hline 2 & $\begin{array}{l}\text { Коэффициент теплоотдачи от } \\
\text { горячих газов к нижней } \\
\text { поверхности плиты }\end{array}$ & 25,0 & $\begin{array}{l}\mathrm{BT} /\left(\mathrm{M}^{2}\right. \\
\mathrm{K})\end{array}$ & {$[1]$} \\
\hline 3 & $\begin{array}{l}\text { Коэффициент теплоотдачи от } \\
\text { верхней необогреваемой } \\
\text { поверхности плиты в } \\
\text { окружающий воздух }\end{array}$ & 4,0 & $\begin{array}{l}\mathrm{BT} /\left(\mathrm{M}^{2}\right. \\
\mathrm{K})\end{array}$ & {$[1]$} \\
\hline
\end{tabular}

При расчете в режиме реального пожара коэффициент теплоотдачи от горячих газов к нижней поверхности плиты принимался равным 35,0 Вт/( $\left.{ }^{2} \mathrm{~K}\right)$.

Обращенная вниз поверхность, обтекаемая раскаленным воздухом, воспринимает теплоту путем совместного конвекционного и радиационного теплообмена. По объему конструкции тепло распространяется от нагретой поверхности к поверхности охлаждения теплопроводностью, а верхняя поверхность плиты отдает теплоту в окружающую среду путем конвекционного и радиационного теплообмена.

После проведения теплотехнического расчета элементов железобетонной плиты в 
модуле Transient Thermal, полученные при нестационарном расчете поля температур в бетоне и арматуре плиты, импортируются в модуль прочностных расчетов Static Structural. Нелинейные расчеты проводятся с использованием итерационной процедуры Ньютона-Рафсона с автоматическим изменением шага.

Результаты

исследования.

Протестированные плиты имели размеры в плане $5900 \mathrm{Mм}^{2}$ х $3900 \mathrm{Mм}^{2}$ и толщину 180 мм. Плита изготовлена из бетона с карбонатным заполнителем. Арматура Ø8 мм установлена с шагом 100 мм в обоих направлениях плиты. Защитный слой бетона толщиной 20 мм. Расстояние от

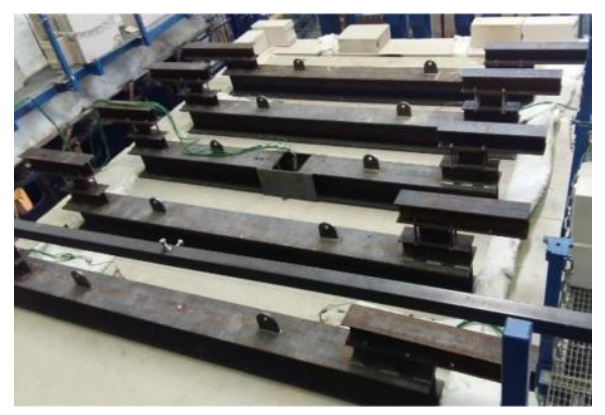

Рисунок 5 - Нагружение плиты при испытаниях [21] обогреваемой поверхности плиты до оси арматуры 24 мм. При стандартном температурном режиме влажность на день испытания (98 день) составила 5,2\%, а прочность бетона на сжатие 41 МПа. При температурном режиме реального пожара влажность на день испытания (391 день) составила 4,2\%, а прочность бетона на сжатие 40 МПа.

Плита была установлена над горизонтальным отверстием печи так, что расстояние между опорами составляло 5600 мм. Нагружена равномерно распределенной нагрузкой 1,3 кН/ $\mathbf{M}^{2}$ (рис. 5). Расчетная схема плиты представлена на рис. 6 .

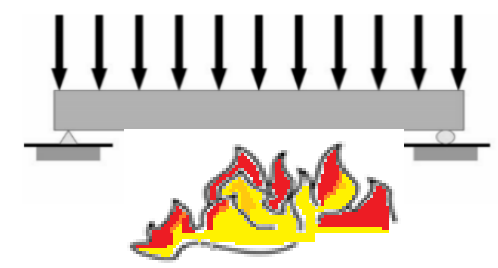

Рисунок 6 - Расчетная схема плиты перекрытия 


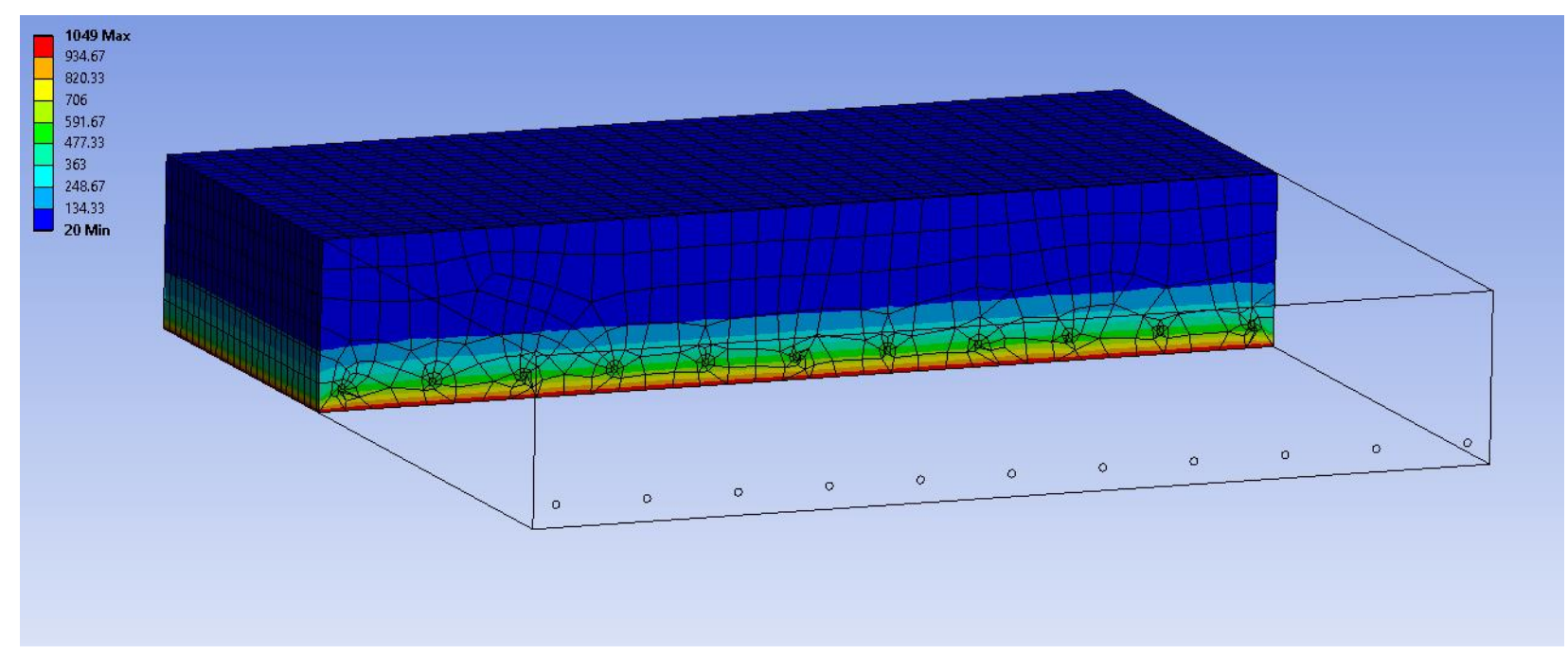

Рисунок 7 - Распределение полей температур во фрагменте плиты на 120 минуте стандартного температурного режима

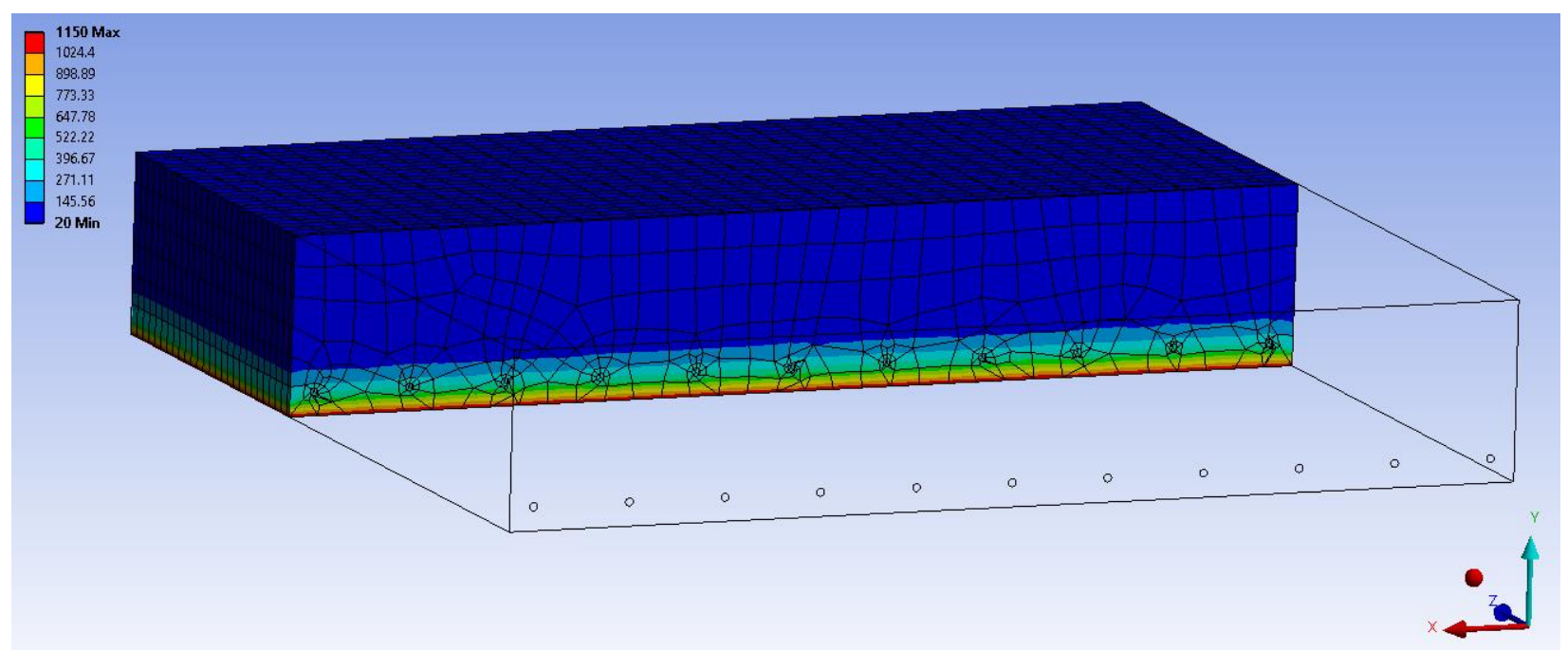

Рисунок 8 - Распределение полей температур во фрагменте плиты на 60 минуте температурного режима реального пожара [23]

Распределение полей температуры во фрагменте плиты на 120 минуте стандартного температурного режима и на 60 минуте температурного режима реального пожара представлены на рисунках 7 и 8.

У табл. 2 приведены значения температур в бетоне плиты, полученные в результате расчета на 120 минуте стандартного температурного режима, в сопоставлении с экспериментальными данными [21].

Таблица 2 - Расчетные и экспериментальные значения температур в бетоне плиты перекрытия на 120 минуте стандартного температурного режима

\begin{tabular}{|l|c|c|c|}
\hline $\begin{array}{l}\text { Расстояние от } \\
\text { обогреваемой } \\
\text { поверхности }\end{array}$ & $100 \mathrm{мm}$ & $200 \mathrm{мm}$ & $300 \mathrm{Mм}$ \\
\hline Эксперимент & 705 & 620 & 490 \\
\hline Модель ANSYS & 741 & 596 & 480 \\
\hline Разница, \% & 5 & -4 & -2 \\
\hline
\end{tabular}


У табл. 3 приведены значения температур в бетоне плиты, полученных в результате расчета на 60 минуте реального пожара, в сопоставлении с экспериментальными данными [21].

Таблицуа 3 - Расчетные и экспериментальные значения температур в бетоне плиты перекрытия на 60 минуте температурного режима реального пожара

\begin{tabular}{|l|c|c|c|}
\hline $\begin{array}{l}\text { Расстояние от } \\
\text { обогреваемой } \\
\text { поверхности }\end{array}$ & 100 мм & 200 мм & 300 мм \\
\hline Эксперимент & 680 & 490 & 360 \\
\hline Модель ANSYS & 700 & 463 & 356 \\
\hline Разница, \% & 3 & -6 & -1 \\
\hline
\end{tabular}

Результаты теплотехнических расчетов в ANSYS оказались достаточно близкими к результатам натурных экспериментов. По результатам сравнения теплотехнических расчетов в ANSYS с экспериментами разница между ними не превышает $6 \%$.

При нагреве плиты и увеличения времени воздействия высоких температур увеличивается прогиб плиты (рисунки 9,10).

При расчетах в ANSYS максимальный прогиб плиты в середине пролета между опорами на 120 минуте воздействия стандартного температурного режима составил 273 мм, а при воздействия температурного режима реального пожара на 60 минуте составил 254 мм.

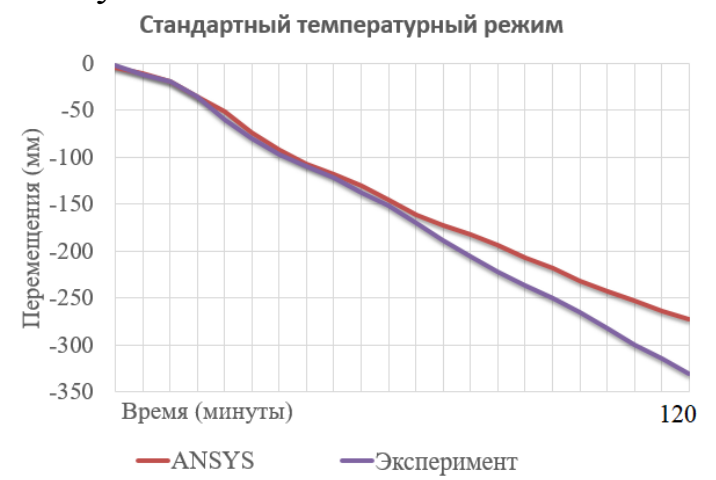

Рисунок 9 - Прогиб в середине пролета железобетонной плиты при стандартном

режиме

температурном

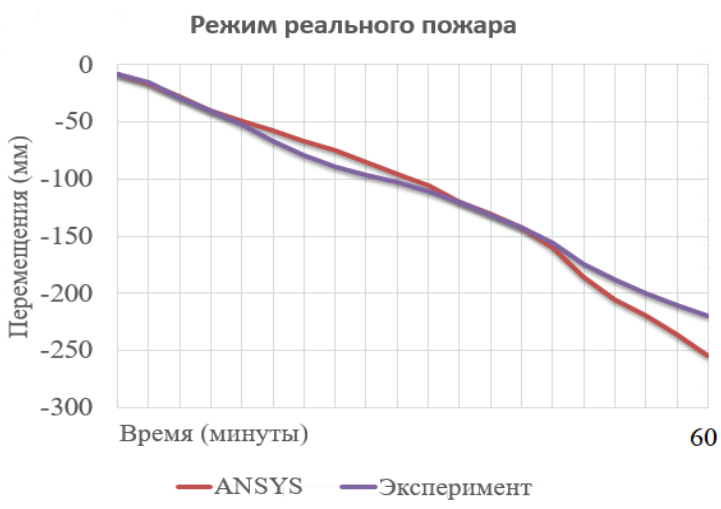

Рисунок 10 - Прогиб в середине пролета железобетонной плиты при температурном режиме реального пожара

Максимальное отличие результатов расчетов в ANSYS от прогибов, полученных при натурных огневых испытаниях [21], составляет соответственно $17 \%$ и $15 \%$. Результаты проведенных расчетов хорошо согласуются с экспериментальными данными.

$\begin{array}{lr}\quad \text { Разработана } & \text { методика } \\ \text { исследования } & \text { численного } \\ \text { деформированного } & \text { напряженно- } \\ \text { состояния }\end{array}$ железобетонных конструкций перекрытий с учетом нестационарных полей температур в арматуре и бетоне при стандартном температурном режиме и температурном режиме реального пожара. При этом используются характеристики материлов, приведенные в ДСТУ-Н Б ЕN 1992-1-2, а также исходные данные, необходимые для применения уточненного метода расчета. Эти данные устанавливаются путем анализа имеющихся в литературе экспериментальных данных и характеристик материалов, приведенных в Еврокодах. На примере расчета на огнестойкость железобетонной плиты перекрытия проведены расчеты с реализацией связанных термопрочностных задач в программном комплексе ANSYS. Результаты расчетов сопоставлены с экспериментальными данными. Использование предлагаемого 
метода позволяет достаточно точно оценить огнестойкость железобетонных конструкций и прогнозировать их напряженнодеформированное состояние при пожаре.

\section{Выводы и направления последующих исследований.}

Моделирование нестационарных высокотемпературных воздействий при стандартном температурном режиме, температурном режиме реального пожара и сложного напряженно-деформированного состояния опытных образцов железобетонных плит перекрытий путем нелинейного конечно-элементного расчета на огнестойкость с помощью программного комплекса ANSYS дает возможность численно воспроизвести результаты эксперимента.

Результаты численного моделирования хорошо согласуются с экспериментальными данными [21]. С помощью предлагаемого метода, используя новые национальные стандарты, гармонизированные с Еврокодами, программный комплекс ANSYS, a также учитывая данные, отсутствующие в ДСТУ-Н Б ЕN 1992-1-2, и установленные путем анализа имеющихся в литературе экспериментальных данных и характеристик материалов, приведенных в Еврокодах, можно достаточно точно оценить огнестойкость железобетонных конструкций и прогнозировать их напряженно-деформированное состояние при пожаре.

\section{СПИСОК ИСПОЛЬЗОВАННЫХ ИСТОЧНИКОВ}

1. ДСТУ-Н Б ЕN 1992-1-2:2012 Єврокод 2. Проектування залізобетонних конструкцій. Частина 1-2. Загальні положення. Розрахунок конструкцій на вогнестійкість (EN 1992-1-2:2004, IDT). [Чинний від 2013-07-01]. Вид. офіц. Київ.

2. Демчина Б. Г., Коляков М. Й. До питання розрахунку вогнетривкості залізобетонних конструкцій. Збірник тез першої всеукраїнської науковотехнічної конферениї "Науковопрактичні прорблеми сучасного залізобетону. Київ.: 1996. С. 99 - 101.

3. Клованич С.Ф. Модель деформирования железобетона и расчет конструкций при сложном напряженном состоянии и нагреве: дис. д-ра техн. наук. 05.23.01. Москва, 1990. 404 с.

4. Милованов А.Ф. Работа железобетонных конструкций при высоких температурах. М., Стройиздат, 1972. 160 с.

5. Ройтман М.Я. Противопожарное нормирование в строительстве. М. :Стройиздат, 1985. 590 с.

6. Фомин С. Л. Методика расчета огнестойкости монолитных зданий с безригельными каркасами. Міжвідомчий наук.-техн. зб. наук. пращь (будівництво). / Державне підприємство «Державний науково-дослідний інститут будівельних конструкцій» Міністерства регіонального розвитку та будівництва України. Вип.74: в 2-х кн.: Книга 1. К.: ДП НДІБК, 2011. С. $228-239$.

7. Яковлев А. И. Расчет огнестойкости строительных конструкций. М.:Стройиздат, 1988. 143 с.

8. Kodur, V.K.R., Agrawal, A. An approach for evaluating residual capacity of reinforced concrete beams exposed to fire Engineering Structures. J. of Engineering Structures, V. 110, 2016. p. 293 306

9. Thomas Gernaya, Alain Millardb and Jean-Marc Franssenc A multiaxial constitutive model for concrete in the fire situation: Theoretical formulation. International Journal of Solids and Structures.V 50, I. 22-23, 2013, p. 3659-3673.

10. Альтшулер В.А. Упругопластические характеристики бетона при нагреве под нагрузкой.«Бетон и железобетон». 1974 № 9. С. $11-12$.

11. Корсун В. И. Напряженнодеформированное состояние железобетонных конструкций в условиях температурных воздействий. Макеевка : ДонГАСА, 2004. 153 с.

12. Кричевский А. П. Расчет железобетонных инженерных сооружений на температурные воздействия.М.: Стройиздат, 1984. 148 с.

13. Schneider, U.: Concrete at high temperature A general review, Fire Safety Journal, The Netherlands, 1988, p. $55-68$. 
14. Y. Anderberg. The Effects of the Constitutive Models on the Prediction of Concrete Mechanical Behaviour and on the Design of Concrete Structures Exposed to Fire. Proceedings of the Workshop. Fire Design of Concrete Structures: What now? What next? Milan, Italy, December 2-3, 2004. p. 37 $-47$.

15. R. Jansson, Measurement of concrete thermal properties at high temperatures - Brandforsk project 328-031, SP Swedish National Testing and Research Institute, 2004. 90 p.

16. Drucker, D. C., W. Prager. "Soil Mechanics and Plastic Analysis or Limit Design." Quarterly of Applied Mathematics. 10.2 (1952): $157-165$.

17. ДСТУ-Н Б ЕN 1993-1-2:2010 Єврокод 3. Проектування сталевих конструкцій. Частина 1-2. Загальні положення. Розрахунок конструкцій на вогнестійкість (EN 1993-1-2:2005, IDT).

18. ДСТУ-Н Б ЕN 1994-1-2:2012 Сврокод 4. Проектування сталезалізобетонних конструкцій. Частина 1-2. Загальні правила. Розрахунок конструкцій на вогнестійкість (EN 1994-1-2:2005, IDT).

19. Корсун В. І., Нєдорєзов А. В., Макаренко С. Ю. Порівняльний аналіз критеріїв міцності для бетонів. Сучасне промислове та цивільне будівництво. 2014. Т. 10, № 1. С. 65 - 78.

20. ANSYS Element Reference. ANSYS Release 19.1 Documentation. ANSYS Inc., 2019.

21. Siyimane Mohaine, Nataša Kalaba, Jean-Marc Franssen, Luke Bisby, Alastair Bartlett, JeanChristophe Mindeguia, Robert McNamee, Jochen Zehfuss \& Fabienne Robert. Thermal and mechanical response of reinforced concrete slabs under natural and standard fires. Proceedings of the 6th International Workshop on Concrete Spalling due to Fire Exposure. Sheffield, United Kingdom, 19-20 September 2019. 320 p.

\section{REFERENCES}

1. DSTU-N B EN 1992-1-2:2012 Yevrokod 2. Proektuvannia zalizobetonnykh konstruktsii. Chastyna 1-2. Zahalni polozhennia. Rozrakhunok konstruktsii na vohnestiikist (EN 1992-1-2:2004, IDT). [Chynnyi vid 2013-07-01]. Vyd. ofits. Kyiv [in Ukrainian].

2. Demchyna B. H., Koliakov M. Y. (1996) Do pytannia rozrakhunku vohnetryvkosti zalizobetonnykh konstruktsii. Zbirnyk tez pershoi vseukrainskoi naukovotekhnichnoi konferentsii "Naukovopraktychni prorblemy suchasnoho zalizobetonu" Kyiv.: 1996. S. 99 - 101 [in Ukrainian].

3. Klovanych S. F. (1990) Model deformyrovanyia zhelezobetona y raschet konstruktsyi pry slozhnom napriazhennom sostoianyy y nahreve: dys. d-ra tekhn. nauk. 05.23.01. Moskva, 1990. 404 s. [in Russian].

4. Mylovanov A.F. (1972) Rabota zhelezobetonnыkh konstruktsyi pry vыsokykh temperaturakh. M., Stroiyzdat.160 s. [in Russian].

5. Roitman M.Ia. (1985) Protyvopozharnoe normyrovanye v stroytelstve. M. :Stroiyzdat. 590 s. [in Russian].

6. Fomyn S. L. (2011) Metodyka rascheta ohnestoikosty monolytnыkh zdanyi s bezryhelnыmy karkasamy. Mizhvidomchyi nauk.-tekhn. zb. nauk. prats (budivnytstvo) / Derzhavne pidpryiemstvo «Derzhavnyi naukovo-doslidnyi instytut budivelnykh konstruktsii» Ministerstva rehionalnoho rozvytku ta budivnytstva Ukrainy. Vyp.74: v 2-kh kn.: Knyha 1. - K.: DP NDIBK. S. 228-239 [in Russian].

7. Iakovlev A. Y. Raschet ohnestoikosty stroytelnbkh konstruktsyi. M.:Stroiyzdat, 1988. - 143 s. [in Russian].

8. Kodur, V.K.R., Agrawal, A. (2016) An approach for evaluating residual capacity of reinforced concrete beams exposed to fire Engineering Structures. J. of Engineering Structures, V. 110. p. 293 306 [in English].

9. Thomas Gernaya, Alain Millardb and Jean-Marc Franssenc (2013) A multiaxial constitutive model for concrete in the fire situation: Theoretical formulation. International Journal of Solids and Structures.V 50, I. 22-23. p. 3659-3673 [in English].

10. Altshuler V.A. Upruhoplastycheskye kharakterystyky betona pry nahreve pod nahruzkoi.-«Beton y zhelezobeton». 1974 №9. S. 11-12 [in Russian]. 
11. Korsun V. Y. (2004) Napriazhennodeformyrovannoe sostoianye zhelezobetonnыkh konstruktsyi v uslovyiakh temperaturnыkh vozdeistvyi [Tekst] / V. Y. Korsun. - Makeevka : DonHASA.153 s. [in Russian].

12. Krychevskyi A. P. (1984) Raschet zhelezobetonnыkh ynzhenernыkh sooruzhenyi na temperaturnыe vozdeistvyia.M.: Stroiyzdat.148 s. [in Russian].

13. Schneider, U.: Concrete at high temperature A general review, Fire Safety Journal, The Netherlands, 1988, p. 55-68 . [in English].

14. Y. Anderberg (2004) The Effects of the Constitutive Models on the Prediction of Concrete Mechanical Behaviour and on the Design of Concrete Structures Exposed to Fire. Proceedings of the Workshop. Fire Design of Concrete Structures: What now? What next? Milan, Italy, December 2-3, 2004. r. 37-47 [in English].

15. R. Jansson (2004) Measurement of concrete thermal properties at high temperatures. Brandforsk project 328-031, SP Swedish National Testing and Research Institute. 90 r. [in English].

16. Drucker, D. C., W. Prager (1952). Soil Mechanics and Plastic Analysis or Limit Design. Quarterly of Applied Mathematics. 10.2: 157-165 [in English].

17. DSTU-N B EN 1993-1-2:2010 Yevrokod 3. Proektuvannia stalevykh konstruktsii. Chastyna 1-2. Zahalni polozhennia. Rozrakhunok konstruktsii na vohnestiikist (EN 1993-1-2:2005, IDT) [in Ukranian].

18. DSTU-N B EN 1994-1-2:2012 Yevrokod 4. Proektuvannia stalezalizobetonnykh konstruktsii. Chastyna 1-2. Zahalni pravyla. Rozrakhunok konstruktsii na vohnestiikist (EN 1994-1-2:2005, IDT) [in Ukranian].

19. Korsun V. I. (2014) Porivnialnyi analiz kryteriiv mitsnosti dlia betoniv / V. I. Korsun, A. V. Niedoriezov, S. Yu. Makarenko // Suchasne promyslove ta tsyvilne budivnytstvo. 2014. T. 10, № 1. S. 65 - 78 [in English].

20. ANSYS Element Reference. ANSYS Release 19.1 Documentation. ANSYS Inc., 2019 [in English].

21. Siyimane Mohaine, Nataša Kalaba, Jean-Marc Franssen, Luke Bisby, Alastair Bartlett, JeanChristophe Mindeguia, Robert McNamee, Jochen Zehfuss \& Fabienne Robert. Thermal and mechanical response of reinforced concrete slabs under natural and standard fires. Proceedings of the 6th International Workshop on Concrete Spalling due to Fire Exposure. Sheffield, United Kingdom, 19-20 September 2019.320 p. [in English].

\section{REINFORCED CONCRETE SLAB CALCULATION UNDER EXPOSURE TO INCREASED FIRE TEMPERATURES}

V. Poklonskyi ${ }^{1}$, P. Krukovslyi ${ }^{1}$, S. Novak ${ }^{2}{ }^{1}$

${ }^{1}$ Institute of Engineering Thermophysics of the National Academy of Sciences of Ukraine

${ }^{2}$ leading researcher of the research and testing center, Institute of Public Administration and Research in Civil Protection

\section{KEYWORDS ANNOTATION}

fire resistance, reinforced concrete structures, standard fire, natural fire, numerical modelling
For the stress-strain state numerical researches of reinforced concrete floor structures considering non-stationary temperature fields in reinforcement and concrete at a standard temperature regime and a real fire temperature regime a method has been developed. A characteristics of the materials given in DSTU-N B EN 1992-1-2 are used as part of the methodology, as well as the necessary for the application of refined calculation method initial data. These data are established by available in literature experimental data analyzing and given in Eurocodes material characteristics. Assessing the structures fire resistance, the refined calculation method takes into account all the factors that have a significant effect on the structure stress-strain state during a fire. The increasing and distribution of temperature in the structure at a given moment in time (heat engineering calculation) and the mechanical behavior of the structure (static calculation) is 
determined, taking into account the corresponding fire scenario. The technique is illustrated by the reinforced concrete floor slab fire resistance calculating example. Calculations with the related thermal strength tasks implementation in the ANSYS software package have been carried out. The reinforced concrete floor slab design was carried out in the Design Modeller ANSYS software module.

Then, the calculations were carried out sequentially in the TRANSIENT THERMAL and STATIC STRUCTURAL modules. Concrete and reinforcement were modeled by volumetric elements. The approach does not require finite element mesh binding to the reinforcement spacing, which allows it to be applied to real dimensions' tasks. In the concrete model, the yield surface consists of two intersecting Drucker-Prager conical surfaces. The calculation results are in good agreement with the presented literature experimental data. The proposed method usage makes it possible to assess the reinforced concrete structures fire resistance sufficiently accurate and predict its stress-strain state during fire.

РОЗРАХУНОК ЗАЛІЗОБЕТОННИХ ПЛИТ ПЕРЕКРИТТЯ ПРИ ДІЇ ПІДВИЩЕНИХ ТЕМПЕРАТУР НА ПОЖЕЖІ

Поклонський В.Г. ${ }^{1 *}$, Круковський П.Г. ${ }^{1}$, Новак С. В. ${ }^{2}$

${ }^{1}$ Інститут технічної теплофізики Національної академії наук України

${ }^{2}$ Інститут державного управління та наукових досліджень з ичивільного захист КЛЮЧОВІ СЛОВА: АНОТАЦІЯ

вогнестійкість, залізобетонні конструкції, стандартний температурний режим, температурний режим реальної пожежі, чисельне моделювання
Розроблено методику чисельного дослідження напруженодеформованого стану залізобетонних конструкцій плит перекриттів з урахуванням нестаціонарних полів температур в арматурі i бетоні за стандартним температурним режимом $\mathrm{i}$ температурному режимі реальної пожежі. В рамках методики використовуються характеристики материлов, наведені в ДСТУ-Н Б EN 1992-1-2, а також вихідні дані, необхідні для застосування уточненого методу розрахунку. Ці дані встановлюються шляхом аналізу наявних в літературі експериментальних даних i характеристик матеріалів, наведених в Єврокодах. При оцінці вогнестійкості конструкцій уточненим методом розрахунку враховуються всі фрактори, які справляють істотний вплив на напружено-деформований стан конструкції при пожежі. Визначають підвищення і поширення температури в конструкції в заданий момент часу (теплотехнічний розрахунок) і механічну поведінку конструкції (статичний розрахунок), при цьому враховується відповідний сценарій пожежі. Методика ілюструється на прикладі розрахунку на вогнестійкість залізобетонної плити перекриття. Проведено розрахунки 3 реалізацією пов'язаних термопрочностних завдань в програмному комплексі ANSYS. Проектування залізобетонної плити перекриття виконувалося в модулі Design Modeller програми ANSYS. Потім здійснювалися послідовно розрахунки в модулях TRANSIENT THERMAL i STATIC STRUCTURAL. Бетон і арматура моделюються об'ємними елементами. Підхід не вимагає прив'язки сітки кінцевих елементів до кроку арматури, що дозволяє застосовувати його до завдань з реальними розмірами. У прийнятій моделі бетону поверхня плинності складається 3 двох пересічних конічних поверхонь Друкера-Прагера. Результати розрахунків добре узгоджуються з представленими літературними експериментальними даними. Використання запропонованої методики дозволяє досить точно оцінити вогнестійкість залізобетонних конструкцій і прогнозувати їх напружено-десрормований стан при пожежі. 